\title{
Efficacy of turmeric (Curcuma longa) and garlic (Allium sativum) on Eimeria species in broilers
}

\author{
A.O. El-Khtam *, Amera Abd El Latif, M.H. El-Hewaity \\ Department of Parasitology, Fac. Vet. Med. Sadat City University, Egypt \\ *Corresponding author E-mail: elbahy7@yahoo.com
}

Copyright $\odot 2014$ A.O. El-Khtam et al. This is an open access article distributed under the Creative Commons Attribution License, which permits unrestricted use, distribution, and reproduction in any medium, provided the original work is properly cited.

\begin{abstract}
In this study, powders were evaluated for their anticoccidial effects. In in vitro, sporulated oocysts of mixed Eimeria species isolated from naturally infected chickens were randomly assigned to $10,5,2.5,1.25,0.6,0.3,0.2$ and $0.08 \mathrm{~g}$ turmeric and garlic powders /liter distilled water $(\mathrm{g} / \mathrm{L}$ ). The efficacy of garlic was higher (up to $80 \%$ ) than turmeric (up to $66.6 \%)$ at different concentrations. In the in vivo study, one-day old chicks were divided into 7 equal groups. All groups were infected with 10.000 viable sporulated oocysts of mixed Eimeria spp. orally except G7 (-ve control). G1 and G2 were infected and supplemented with turmeric powder at 10 and $5 \mathrm{~g} / \mathrm{L}$, respectively, G3 and G4 were infected and supplemented with garlic powder at 10 and $5 \mathrm{~g} / \mathrm{L}$, respectively. G5 was infected and treated with Amprolium at $1.25 \mathrm{~g} / \mathrm{L}, \mathrm{G} 6$ (+ve control) infected, non-treated and G7 was non-infected \& non-treated. Clinical signs and lesion score were less sever in garlic supplemented groups compared with turmeric supplemented groups. Reduction of total oocyst count in garlic supplemented group more than turmeric supplemented group. It is concluded that Garlic powder was more effective than turmeric powder in treatment and control of coccidiosis.
\end{abstract}

Keywords: Chicken Coccidiosis, Turmeric, Garlic, Anticoccidial Effect.

\section{Introduction}

Coccidiosis is a major disease problem in the poultry industry. It is a parasitic disease of the intestinal tract of animals caused by single-cell protozoa. Coccidian organisms can infect humans, birds, and livestock, as they are usually species-specific. Coccidiosis in the poultry industry is caused by any of the species of the genus Eimeria, individually or in combination. Outbreaks usually result in enormous economic losses as a result of the associated morbidity and mortality [1]. It leads to the extensive destruction of the intestinal epithelium which results in reduced food efficiency and body weight gain, as well as a temporary reduction in egg production [2], [3]. This has a considerable economic loss at the level of poultry industry. The three most common species of Eimeria that affect the poultry industry are Eimeria tenella, Eimeria maxima, and Eimeria acervulina [4]. Eimeria infection is transmitted through hardy, thickwalled sporulated oocysts which able to survive for lengthy periods in the poultry litter and soil particles. Coccidiosis is mainly controlled by the hygienic measures and the use of chemotherapeutic agents or chemical anticoccidial agents [5] However, the development of drug resistance to all the drugs introduced so far by the causative parasites and the escalating cost of drug development have greatly reduced the commercial incentive to develop new chemical anticoccidials [1], [6], [7], [8], [9], [10], [11]. Moreover, nowadays, consumers request poultry products that are free from residual antiparasitic drugs [12]. Consequently, the development of alternative, safer and environmentally friendly anticoccidial agents have become priority in most parts of the world [13]. The use of natural products as an alternative to drugs may be the best solution to this consumer demand. Many studies have reported the in vivo efficiency of natural plant extracts in the treatment of coccidiosis [14], [15], and [16]. Garlic (Allium sativum) and turmeric (Curcuma longa) were widely used to cure and prevent diseases in human beings [17, 18].

Turmeric (Curcuma longa) is a tropical plant native to southern and southeastern tropical Asia. The main yellow bioactive substances isolated from the rhizomes of Curcuma are curcumin, demethoxycurcumin and bisdemethoxycurcumin which are present to the extent of $2-5 \%$ of the total spice in turmeric powder. Curcumin is the 
main important bioactive ingredient responsible for the biological activity of curcuma. Curcumin has been shown to have several biological effects, exhibiting anti-inflammatory [19], antioxidant [20] and hypolipidaemic [21] activities. Curcumin has also been studied extensively as a chemopreventive agent in several cancers [22]. Additionally, it has been suggested that curcumin possess hepatoprotective, antitumor, antiviral and anticancer activity [23]. It is used in gastrointestinal and respiratory disorders [24]. The significant biological properties of turmeric powder make it a potential substitute for in feed antibiotics in livestock diets.

Garlic (Allium sativum) is grown in many areas throughout the world and is considered by herbalists to be one of the most essential and useful herbs used for medicinal purposes. There are numerous reports indicating the efficacy of garlic in the prevention and treatment of a variety of diseases and for validating its traditional uses. For instance, garlic has been described to exhibit broad antimicrobial activity against bacteria ,fungi and virus [25], [26], [27], antitumor activity [28], as well as antithrombotic, antiarthritic, hypolipidemic, and hypoglycemic activities [30, 31] Moreover, garlic has been reported to be effective against diverse parasites such as Amoeba [32], Leishmania [33], Trypanosoma [34] and Cryptosporidium [35]. The efficacy of garlic on Coccidia infections has been reported in rabbits [36]. In Chinese herbal medicine, garlic is used to prevent influenza, relieve toxicities, and kill parasites such as roundworms and tapeworms [37]. Freshly crushed Garlic (Allium sativum) contains allicin, alliin, ajoene, diallylsulfide, dithiin, Sallylcysteine. Ahsan et al. [38] reported that feed added Garlic can upgrade immune performance against IBD and ND in poultry.

This study is a part of a programme aiming to find alternative strategies to synthetic coccidiostats for treatment and control of coccidiosis in chicken using medicinal plants (natural products). The objective of this study was to evaluate the efficacy of turmeric and garlic powders against mixed Eimeria species through in vitro and in vivo experimental designs.

\section{Materials and methods}

\subsection{Plant materials}

Garlic (Allium sativum) and Turmeric (Curcuma longa) powders were purchased from a local source.

\subsection{Experimental drug}

Amprolium (Amproxine 20\%, Water soluble powder, Pharma swede Pharmaceuticals company Ltd., Egypt) a commercially available anticoccidial drug for the routine treatment of avian coccidiosis (due to Eimeria species) was used to compare the anticoccidial effects of the plant powders.

\subsection{Eimeria spp. strains}

The challenge oocysts were isolated from the intestine and ceci of naturally infected chickens. The oocysts were separated by using sieving and sedimentation techniques [39]. The collected oocysts were allowed to sporulate at room temperature in $2.5 \%$ potassium dichromate solution. . The sporulated Eimeria oocysts were cleared and counted per 1.0 $\mathrm{ml}$ of the solution using the McMaster technique as described by Soulsby [39]. The collected field strains of sporulated Eimeria oocysts were kept at the Dept. of Parasitology, Faculty of Veterinary Medicine, and University of Sadat City until their use for in- vitro and in vivo studies. Mixture of the oocysts used consists of E. tenella 30\%, E. maxima 20\%, E. acervulina $20 \%$, and E. neatcrix $15 \%$, and E. mitis $15 \%$.

\subsection{Chickens}

One-hundred and forty one-day old Hubbard broiler unsexed chicks were obtained from a local commercial broiler hatchery and used in the trial. The birds were kept under good hygienic measures. Drinking water offered ad libitum. Chicks were fed on balanced commercial ration free from anticoccidials. The chicks were floor reared in separate units along the experimental period. Faeces were examined microscopically to insure that they are free from coccidiosis.

\subsection{In vitro study of garlic and turmeric efficacy}

Different concentrations from Garlic powder [40] and Turmeric powder [41] $(10,5,2.5,1.25,0.6,0.3,0.2$ and $0.08 \mathrm{~g}$ /liter dist. water) were prepared. For comparison, Amprolium was used at the recommended concentration (1.25g/liter) as reference drug. Separate Petri dishes containing $10 \mathrm{ml}$ of each concentration of plant powders were inoculated with equal number of viable sporulated oocysts and incubated at $25^{\circ} \mathrm{C}$ and examined after $1 \mathrm{hr}, 6 \mathrm{hr}$ and $18 \mathrm{hr}$. from incubation. The Efficacy of tested plant powders was calculated according to the following equation:-

Efficacy $=1-$ death $/$ total $\%$. 


\subsection{In vivo study of garlic and turmeric efficacy}

\subsubsection{Experimental design}

A total of one-hundred and forty one - day old Hubbard broiler chicks were randomly divided at $1^{\text {st }}$ day of age into seven equal groups (from G1 to G7), each of 20 chicks, the groups were arranged as the following:

Group 1: Infected and supplemented with turmeric powder at $10 \mathrm{~g} /$ liter drinking water.

Group 2: Infected and supplemented with turmeric powder at $5 \mathrm{~g} / /$ liter drinking water.

Group 3: Infected and supplemented with garlic powder at $10 \mathrm{~g} / /$ liter drinking water.

Group 4: Infected and supplemented with garlic powder at $5 \mathrm{~g} / /$ liter drinking water

Group 5: Infected and treated Amprolium powder at $1.25 \mathrm{~g} /$ liter drinking water.

Group 6: Infected - non treated (isolated control positive).

Group 7: Non infected - non treated (control negative).

All groups except group 7 were infected with 10,000 sporulated oocysts / bird orally of mixed Eimeria spp. at $3^{\text {rd }}$ day old age (zero days). Treatment by drugs started at the same day of infection ( $3^{\text {rd }}$ day of age) in the drinking water ( 8 hrs per day after thirst for one hour) till the end of experiment $\left(14^{\text {th }}\right.$ day of age).

Evaluation of the tested powders efficacy

\subsubsection{Clinical examination}

The clinical signs as depression, ruffled feathers, bloody diarrhea, loss of appetite were recorded during experimental period.

\subsubsection{Mortality rate}

The daily number of dead birds as a result of coccidial infection were recorded and calculated as a percentage of mortality.

\subsubsection{Parasitological examination (Oocysts count)}

Fresh fecal droppings were collected from the litter spread on the ground from each group for oocysts count daily from $5^{\text {th }}$ till $9^{\text {th }}$ dpi. When only few or no oocysts could be detected in fecal droppings (related to oocysts shedding curve of the control group). The mean number of oocysts per gram feces for each group was counted using the Mc Master counting technique according to the method described by Long and Joyner [42].

\subsubsection{Post mortem examination}

It was carried out at $5^{\text {th }}, 7^{\text {th }}, 9^{\text {th }}, 11^{\text {th }}$ d.p.i. Three birds from each group were randomly picked up for P.M. examination as well as all birds that died during the experiment. Lesion scores were determined by macroscopic examination of the intestine and ceci of each bird according to [40]. Lesion score was 0 when no evident lesions were detected while a score 3 referred to the severely affected bird.

Table 1: Lesion Score According to [40]

\begin{tabular}{ll}
\hline Grade & Remarks \\
\hline Grade $0(-)$ & - No evident lesions. \\
Grade $1(+)$ & - Light redness of the intestinal wall. \\
& - Mild thickening of the intestinal wall. \\
& - Moderate redness of the intestinal wall. \\
& - Moderate thickening of the intestinal wall. \\
Grade $2(++)$ & - $3-6$ focal lesions in $3 \mathrm{~cm}$ of the intestinal wall. \\
& - Severe congestion of the intestinal wall. \\
& - Increase the thickening of the intestinal wall. \\
Grade $3(+++)$ & Ballooning in the caecum and presence of "bloody cecal core". \\
\hline
\end{tabular}

\subsection{Statistical analysis}

The data obtained were statistically analyzed by analysis of variance (Anova) and comparing groups was performed using the least significant difference (LSD) at $\mathrm{p} \leq 0.05$ according to Petrie and Watson [43] and computerized using SPSS II (2001). 


\section{Results}

\subsection{In vitro study of efficacy of turmeric and garlic powders on oocyst vitality}

The highest efficacy of tested plants powders was recoded after $18 \mathrm{hr}$. post exposure which varied according to different concentrations of the tested powders. Concerning to turmeric powder, the highest efficacy was $66 \%$ at the concentration of $10 \mathrm{~g} / \mathrm{liter}$ distilled water. The lowest efficacy was $60 \%$ at the concentration of $0.08 \mathrm{~g} /$ liter distilled water. Passing through the other used concentrations of turmeric powder $(5,2.5,1.25,0.6,0.3$ and $0.2 \mathrm{~g} /$ liter distilled water), they showed reduced efficacy $(65.22 \%, 65 \%, 64.42 \%, 64 \%, 62 \%$ and $62 \%$ respectively). Concerning to garlic powder, the highest efficacy was $80 \%$ at the concentration of $10 \mathrm{~g} /$ liter distilled water. The lowest efficacy was $71 \%$ at the concentration of $0.08 \mathrm{~g} /$ liter distilled water. Passing through the other used concentrations of garlic powder $(5,2.5,1.25$, $0.6,0.3$ and $0.2 \mathrm{~g} / \mathrm{liter})$, they showed reduced efficacy $(80 \%, 77.75 \%, 76 \%, 75.22 \%, 72.72 \%$ and $71.22 \%)$, respectively. The highest efficacy of Amprolium was $90 \%$ after $18 \mathrm{hr}$ from exposure to the recommended dose. The efficacy of garlic was nearly similar to that of Amprolium and higher than turmeric at different concentrations.

Table 2: Effect of Turmeric and Garlic Powders on Eimeria Oocyst Vitality.

\begin{tabular}{|c|c|c|c|c|}
\hline \multirow{2}{*}{\multicolumn{2}{|c|}{ Concentration /liter distilled water }} & \multicolumn{3}{|c|}{ Exposure time } \\
\hline & & After $1 \mathrm{hr}$. & After $6 \mathrm{hr}$ & After $18 \mathrm{hr}$. \\
\hline \multirow{8}{*}{ 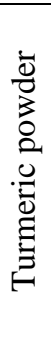 } & $10 \mathrm{~g}$ & $60 \%$ & $65 \%$ & $66 \%$ \\
\hline & $5 \mathrm{~g}$ & $60 \%$ & $64 \%$ & $65.22 \%$ \\
\hline & $2.5 \mathrm{~g}$ & $59.22 \%$ & $64 \%$ & $65 \%$ \\
\hline & $1.25 \mathrm{~g}$ & $59.12 \%$ & $63.55 \%$ & $64.42 \%$ \\
\hline & $0.6 \mathrm{~g}$ & $58 \%$ & $63.25 \%$ & $64 \%$ \\
\hline & $0.3 \mathrm{~g}$ & $57.55 \%$ & $61.2 \%$ & $62 \%$ \\
\hline & $0.2 \mathrm{~g}$ & $57.45 \%$ & $60 \%$ & $62 \%$ \\
\hline & $0.08 \mathrm{~g}$ & $53 \%$ & $58.11 \%$ & $60 \%$ \\
\hline \multirow{8}{*}{ 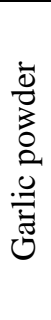 } & $10 \mathrm{~g}$ & $75 \%$ & $80 \%$ & $80 \%$ \\
\hline & $5 \mathrm{~g}$ & $74.2 \%$ & $77 \%$ & $80 \%$ \\
\hline & $2.5 \mathrm{~g}$ & $74 \%$ & $77 \%$ & $77.75 \%$ \\
\hline & $1.25 \mathrm{~g}$ & $73.44 \%$ & $74 \%$ & $76 \%$ \\
\hline & $0.6 \mathrm{~g}$ & $71 \%$ & $75 \%$ & $75.22 \%$ \\
\hline & $0.3 \mathrm{~g}$ & $70 \%$ & $71 \%$ & $72.72 \%$ \\
\hline & $0.2 \mathrm{~g}$ & $70.77 \%$ & $70 \%$ & $71.22 \%$ \\
\hline & $0.08 \mathrm{~g}$ & $70 \%$ & $70.11 \%$ & $71 \%$ \\
\hline \multicolumn{2}{|c|}{ Amprolium (1.25 g) } & $76 \%$ & $83.83 \%$ & $90 \%$ \\
\hline
\end{tabular}

\subsection{In vivo study}

\subsubsection{Clinical signs}

In supplemented and treated groups (G1,G3,G4 and G5), the symptoms were milder than other groups (G2,G6) as birds showed depression, decrease the activity and slight bloody diarrhea at $5^{\text {th }}$ and $7^{\text {th }}$ dpi then returns to the normal condition. Moreover, Group 2 (supplemented with $5 \mathrm{~g}$ turmeric powder /liter drinking water) showed depression, ruffled feathers, bloody diarrhea and mortality rate of (10\%). On the other hand, infected non-treated group (G6) showed ruffled feathers, decrease of appetite, depression, bloody diarrhea, paralysis and mortality rate of $(20 \%)$. Symptoms started from $5^{\text {th }}$ dpi with maximum strength at $7^{\text {th }}$ and $9^{\text {th }}$ d.p.i. and then regression and disappearance of bloody diarrhea till the end of the experiment. Bloody diarrhea and other signs were less severs in garlic supplemented groups than turmeric supplemented groups.

\subsubsection{Lesion score}

The severity of congestion, hemorrhage and ballooning of caeci in garlic supplemented groups (G3 and G4) was less severe compared with turmeric treated groups (G1 and G2). Commonly all infected supplemented and treated groups showed gradual increase of congestion of all intestinal mucosa and the ceaci were ballooned from 5th to 9th dpi. On the other hand, group 6 (infected and non-treated) showed severe congestion, increase in the thickness of the intestinal wall, severe hemorrhage, ballooning in the caeci and presence of bloody cecal core from 5th to 7th d.p.i. The severity of congestion was gradually decreased within 10 and 11th dpi. Furthermore, group 7 (non-infected and non-treated) showed no lesions. 


\subsubsection{Oocysts count}

The highest oocysts count in all infected groups was recorded at 6th, 7th and 8th dpi. There was significant increase in total oocysts count in G6 (infected, non-treated group) $\left(66.8 \pm 0.48 \times 10^{3}\right)$ compared with other groups. Moreover, a significant decrease in total oocysts count in G3 $\left(2.88 \pm 0.07 \times 10^{3}\right)$ and G5 $\left(1.08 \pm 0.03 \times 10^{3}\right)$ compared with other supplemented groups (G1, G2, G4) and infected, non-treated group (G6) $(12 \pm 0.34,21 \pm 0.48,10.67 \pm 0.10$ and $\left.66.8 \pm 0.48 \times 10^{3}\right)$, respectively. Garlic supplemented at $10 \mathrm{~g} / \mathrm{liter}$ and Amprolium induced high reduction in total oocysts count.

Table 3: The Oocysts Count (X $10^{3}$ / G Feces), Mortality (\%) and Lesion Score in Broiler Chickens Experimentally Infected with Mixed Eimeria Spp., and Supplemented with the Tested Powders. (Mean \pm S.E.).

\begin{tabular}{|c|c|c|c|c|c|c|c|}
\hline Time / dpi & G1 & $\mathrm{G} 2$ & G3 & G4 & G5 & G6 & G7 \\
\hline 5 th & $0.5 \pm 0.02^{b}$ & $1 \pm 0.05^{\mathrm{a}}$ & $0.1 \pm 0.01^{\mathrm{d}}$ & $0.27 \pm 0.02^{\mathrm{bc}}$ & $0.1 \pm 0.01^{\mathrm{d}}$ & $0.8 \pm 0.08^{\mathrm{a}}$ & $0.00^{\mathrm{e}}$ \\
\hline 6 th & $3.5 \pm 0.10^{\mathrm{bc}}$ & $4 \pm 0.10^{b}$ & $0.6 \pm 0.03^{\mathrm{e}}$ & $1.2 \pm 0.03^{\mathrm{d}}$ & $0.18 \pm 0.01^{\mathrm{f}}$ & $20 \pm 0.10^{\mathrm{a}}$ & $0.00^{\mathrm{g}}$ \\
\hline 7 th & $4 \pm 0.10^{b c}$ & $6 \pm 0.10^{b}$ & $0.75 \pm 0.01^{\mathrm{d}}$ & $3 \pm 0.09^{c}$ & $0.4 \pm 0.01^{\mathrm{de}}$ & $33 \pm 0.10^{\mathrm{a}}$ & $0.00^{\mathrm{f}}$ \\
\hline 8th & $2 \pm 0.03^{\mathrm{d}}$ & $7 \pm 0.09^{\mathrm{ab}}$ & $1.25 \pm 0.15^{\mathrm{e}}$ & $4.5 \pm 0.10^{c}$ & $0.3 \pm 0.01^{\mathrm{f}}$ & $9 \pm 0.08^{\mathrm{a}}$ & $0.00^{\mathrm{g}}$ \\
\hline 9th & $2 \pm 0.03^{b c}$ & $3 \pm 0.09^{\mathrm{ab}}$ & $0.18 \pm 0.07^{\mathrm{e}}$ & $1.7 \pm 0.02^{\mathrm{d}}$ & $0.1 \pm 0.01^{\mathrm{e}}$ & $4 \pm 0.10^{\mathrm{a}}$ & $0.00^{\mathrm{f}}$ \\
\hline Total & $12 \pm 0.34^{e}$ & $21 \pm 0.48^{b}$ & $2.88 \pm 0.07^{\mathrm{e}}$ & $10.67 \pm 0.10^{\mathrm{cd}}$ & $1.08 \pm 0.03^{\mathrm{ef}}$ & $66.8 \pm 0.48^{a}$ & $0.00^{\mathrm{g}}$ \\
\hline Mortality (\%) & 0.00 & 10.0 & 0.00 & 0.00 & 0.00 & 20.0 & 0.00 \\
\hline Lesion score & ++ & ++ & + & + & - & +++ & - \\
\hline
\end{tabular}

Values are means \pm standard error. Mean values with different letters at the same row differ significantly at $(p \leq 0.05)$.

\section{Discussion}

Coccidiosis is an economic and health problem in the poultry industry and can infect any type of poultry in any type of facility and its occurrence is worldwide [44]. Historically, the severity of experimental Eimeria infection in chickens has been assessed by loss of body weight gain, excretion of fecal oocysts, and the presence of intestinal lesions [45]. These disease parameters reflect host immunity status in avian coccidiosis [46]. The the present study was planned to evaluate an in- vitro efficacy of different concentrations of turmeric and garlic powders on mixed Eimeria oocysts vitality and application of the most effective concentrations in vivo on the experimentally infected with mixed Eimeria species broiler chicks.

The in vitro study revealed that both garlic and turmeric powders induced anticoccidial effect which was concentration dependent and increased by increasing the concentration of the tested powders. Garlic by its high concentration exerted the greatest percentage reduction in oocysts vitality and had high in vitro anticoccdial effect.

The present work showed also the detrimental effect of coccidiosis on clinical signs, mortality rate, lesion scoring and oocysts count after challenging the chicks with oocysts of mixed Eimeria sp. High mortality rate was recorded in the infected non treated group primarily during the first days after inoculation . The detrimental effect of infection was also reflected in the appearance of bloody diarrhea during 4-6 days after infection, the highest total oocysts count recorded in the excreta collected on $5^{\text {th }}, 6^{\text {th }}, 7^{\text {th }}, 8^{\text {th }}$, and $9^{\text {th }}$ d.p.i.. And in the lesion score of the duodenum and cecum recorded at $5^{\text {th }}, 7$ th, 9 th and $11^{\text {th }}$ d.p.i. The tested herbal powders were shown to alleviate the deleterious effect of the experimental infection in chicken. Best results were obtained in groups treated with Amprolium, garlic powders followed by turmeric powder as compared with infected non treated group. The mortality \% was prevented completely in all supplemented groups except in turmeric supplemented group with $(5 \mathrm{~g} / \mathrm{liter})$ decreased compared with infected non treated group. Bloody diarrhea were seen in all the experimental groups, except the uninfected control group, but the extent of bloody diarrhea in the groups supplemented with Amprolium and the tested powders of garlic at concentrations of ( $5 \mathrm{and} 10 \mathrm{~g}$ ) and turmeric at concentration of (10 gram) was milder than that of other groups. The oocysts count and lesion score were zero in uninfected groups. Large number of oocysts was produced in all the infected groups. However, addition of either of the tested plant powders and Amprolium to drinking water of infected chickens significantly decreased the total oocysts count and improve lesion score.

From our results it is concluded that supplementation with powders of either garlic and turmeric exhibits anticoccidial activity which was comparable with that of the anticoccidial drug and evidenced by prevention or reduction of mortality, lowering gut lesion scores and reduced fecal oocyst shedding of the infected chickens as compared to the infected non treated group. These results specially diminished oocyst output suggest that both powders can inhibit or impairs invasion and/ or replication and development of Eimeria parasites species in the gut tissues of chickens before the relatively inert oocysts are formed and finally released (i.e. they effect on the intracellular stages of the infected Eimeria specially at the 2nd schizogony stage (late stages of asexual cycle) as well as those of the sexual stage of Eimeria at the lumen of the intestine). Such an impairment and even inhibition of the intracellular development of parasites by garlic and turmeric are also known to occur with most anticoccidial drugs.

The anticoccidial effect of these tested plant powders may be attributed to their antioxidant effect. Antioxidant compounds could hold promise for the control of Eimeria infections due to the association of coccidial infection with host cell destruction which being associated with oxidative stress and lipid peroxidation of the intestinal mucosa. So, 
antioxidant-rich plants may be lethal to the parasites by inducing oxidative stress and neutralize reactive oxygen species and have potential benefits in treating coccidial infections. According to Allen et al. [47] antioxidant compounds are known to reduce the severity of Eimeria tenella infections by ameliorating the degree of intestinal lipid peroxidation. One of the most potent veterinary anticoccidials, toltrazuril, is believed to achieve some, if not all, of its beneficial effect by limiting the degree of lipid peroxidation [48]. Plants of the genus Curcuma, including C. longa (turmeric), has anti-oxidant and anti-inflammatory properties which could be detrimental for disease outcome and Curcumin is thought to be used to eliminate the intracellular parasites [49], [50], [51], [52]. Moreover, Allen and Danforth [53] concluded that feed supplementations with products that have antioxidant properties such as the spice tumeric (1\%), as well as its main medicinal component, curcumin $(0.05 \%)$ appear effective in reducing upper- and midsmall- intestinal infections caused by E. acervulina and E. maxima. It has been reported that the drinking water supplemented with the different concentrations of the turmeric powder were suppressive towards the development of coccidiosis in chickens [47]. Moreover, the lower oocysts count recorded in the infected groups given the herbal powders was probably due to the presence of the phenolic compounds in the tested herbal powders. Phenols can interact with cytoplasmic membranes and change their cation permeability, leading to impairment of crucial processes in the coccidia cells and, finally, their death [54]. The active compound of turmeric is the phenolic compound curcumin, which has been shown to have antioxidative, anti-inflammatory and immunomodulatory properties [47]. Furthermore, organosulfur compounds present in garlic are the most important contents responsible for most of their pharmacological effects. Among these biologically active compounds, allicin, allyl methyl sulfide, DTS, and ajoene have been shown to be the main responsible compounds for the antifungal, antibacterial, antiprotozoal, and antiviral effects of garlic, respectively [55]. The most important researches showing that elimination from crushed fresh garlic a class of volatile sulphur compounds called thiosulfinates [56]. The sulphur content of the garlic is very close to $1.0 \%$ of its dry weight $(0.35 \%$ of its fresh weight) [57], [58]. The efficacy of sulphur compound against coccidiosis was firstly confirmed by Herrick and Holmes [59]. Also it was confirmed by Saif et al., [60] who recorded that the sulphur compound was used as anticoccidial drug in broilers production from year of 1936 .

The efficacy of the herbs tested in the present trial has previously been evaluated in other experiments. Toulah and AlRawi [36] successfully used garlic extract in treatment of rabbit hepatic coccidiosis. Furthermore, Naidoo et al. [61] reported that several plant extracts as Tulbaghia volrzcea (garlic), Vitis vinifera (grape vine) and Artimisia ofra showed successfully attenuated coccidosis by targeting lipid peroxidation of intestinal mucosa. Similarly, Dkhil et al. [62] concluded that garlic treatment significantly attenuated inflammation and injury of the liver induced by E. papillata infections and oocysts output is significantly decreased in garlic-treated mice. In addition, El-Banna et al. [63] concluded that aqueous extract of Allium sativum and Aloe vera could be used an alternative treatment for controlling avian coccidiosis when added in drinking water in concentration of $100 \mathrm{ppm}$ daily for 5 consecutive days. On the other hand, Allen et al. [47] observed the anticoccidial effect of dietary supplementation of $1 \%$ curcumin in chickens after infection of E. maxima and E. tenella species. Reduced lesion scores and oocyst counts were shown only against E. maxima. Moreover, Fetouh and Naji [64] concluded that Nigella sativa and Curcuma longa either used alone at dose of $1000 \mathrm{ppm}$ or combined with each other at dose of $500 \mathrm{ppm}$ for each in diet have significant anticoccidial activity comparable to / or better than Diclazuril. Furthermore, Yosseff et al. [65] concluded that curcumin treatments relatively minimize the infection, lowered mortality rate and oocyst shedding after 14 days post infection as nearly as Baycox® which is the superior in controlling mortality $(0 \%)$. Similar approach had been done by Abbas et al., [66] who concluded that turmeric powder supplemented to ration of broilers at $3 \%$ conc from day 1 till the end of experiment significantly lowered oocysts count in mild infection of E. tenella. And used as a feed additive for the control of coccidiosis in broilers. In addition, Khalafalla et al. [41] concluded that curcumin exhibited a marked inhibitory effect in vitro on E. tenella sporozoites inducing morphological changes and reducing sporozoite viability and infectivity.

\section{Conclusion}

The results of the present study suggest that supplementation with herbal powders of garlic and turmeric at concentrations of (5 and $10 \mathrm{~g} /$ liter drinking water) partly alleviates the negative impact of Eimeria infection in broiler chickens. The beneficial effect of the herbal powders on the number of oocysts per gram of excreta of the infected chickens was comparable to that exhibited by Amprolium. These effects were highest with garlic. It can be concluded from our data that garlic and turmeric powders exhibits a significant anticoccidial activity and are recommended for control of Coccidiosis.

\section{References}

[1] J.A. Oluyemi and F.A. Roberts, Poultry Production in Warm Wet Climates. 2nd Edn., Spectrum Books, Ibadan, Nigeria, ISBN: 9789780290979, (2000) Pages:190.

[2] W. Min, R.A. Dalloul and H.S. Lillehoj, Application of biotechnological tools for coccidian vaccine development. J. Vet. Sci., 5 (2004) 279 288.

[3] R.A. Dalloul and H.S. Lillehoj Recent advances in immunomodulation and vaccination strategies against coccidiosis. Avian Dis., 49 (2005) 1-8. http://dx.doi.org/10.1637/7306-11150R. 
[4] M.W. Shirley, Eimeria species and strain of chickens, in J. Eckert, R. Braun, M.W. Shirley, P. Coudert (Eds.), Cost 89/820. Biotechnology. Guidelines on Techniques in Coccidiosis Research, The European Commission, (1995) pp. 1-24.

[5] E.J.L. Soulsby, Helminths Arthropods and Protozoa of Domesticated Animals. 7th Edn., Bailliere Tindall, London, UK., (1982) pp: 573-574.

[6] J.F. Ryley, Drug resistance in coccidian. J. Adv. Vet. Sci. Comp. Med., 24 (1980) 99-120.

[7] R.F. Gordon and F.T.W. Jordan, Poultry Diseases. 2nd Edn., American Association of Avian Pathologiest, UK (1982).

[8] H.D. Chapman, Drug resistance in avian coccidia (a review).Vet. Parasitol. 15 (1) (1984) 11-27. http://dx.doi.org/10.1016/0304-4017 (84)90106-7.

[9] H.D. Chapman, Biochemical, genetic and applied aspects of drug resistance in Eimeria parasites of the fowl. Avian Pathol., 26 (1997) 221244. http://dx.doi.org/10.1080/03079459708419208.

[10] A. Permin, Epidemiology Diagnosis and Control of Poultry Parasites. FAO, United Nations, Rome (1998).

[11] H.W. Peek and W.J. Landman, Resistance to anticoccidial drugs of Dutch avian Eimeria spp. fieLC isolates originating from 1996, 1999 and 2001. Avian Pathol. 32 (4) (2003) 391-440. http://dx.doi.org/10.1080/0307945031000121149.

[12] C.G. Harper and A. Makatouni, Consumer perception of organic food production and farm animal welfare. Br. Food J., 104 (2002). 287-299. http://dx.doi.org/10.1108/00070700210425723.

[13] H.J. Youn and J.W. Noh, Screening of the anticoccidial effect of herb extract against Eimeria tenella. Veterinary of Parasitol., 96 (2001) 257263. http://dx.doi.org/10.1016/S0304-4017 (01)00385-5.

[14] I. Giannenas, P. Florou-Paneri, M. Papazahariadou, E. Christaki, N.A. Botsoglou and A.B. Spais, Effect of dietary supplementation with oregano essential oil on performance of broilers after experimental infection with Eimeria tenella. Arch. Tierernahr., 57 (2) (2003) $99-106$.

[15] R. Saini, S. Davis and W. Dudley-Cash, Oregano essential oil reduces the expression of coccidiosis in broilers. Proceeding of the 52nd Conference on Western Poultry Diseases, Sacramento, CA, (2003) pp. 97-98.

[16] E.O. Oviedo-Rondón, M.E. Hume, C. Hernandez and S. Clemente-Hernandez, Intestinal microbial ecology of broilers vaccinated and challenged with mixed Eimeriaspecies, and supplemented with essential oil blends. Poult. Sci., 85 (2006) 854-860. http://dx.doi.org/10.1093/ps/85.5.854.

[17] E.C. Delaha and V.F. Garagusi Inhibition of mycobacteria by garlic extract (Allium sativum).Antimicrob. Agent Chemother., 27 (1985) 485486. http://dx.doi.org/10.1128/AAC.27.4.485.

[18] S. Somasundaram, N.A. Edmund, D.T. Moore, G.W. Small, Y. Shi and R.Z. Orlowski, Dietary curcumin inhibits chemotherapy - induced apoptosis in models of human breast cancer. Cancer Res., 62 (2002) 3868 -3875.

[19] P.R. Holt, S. Katz and R. Kirshoff, Curcumin therapy in inflammatory bowel disease: a pilot study. Digest. Dis. Sci., 50 (2005) $2191-2193$. http://dx.doi.org/10.1007/s10620-005-3032-8.

[20] M. Iqbal, S.D. Sharma, Y. Okazaki, M. Fujisawa and S. Okada, Dietary supplementation of curcumin enhances antioxidant and phase II metabolizing enzymes in ddY male mice: possible role in protection against chemical carcinogenesis and toxicity. Pharmacol. Toxicol., 92 (2003) 33-38. http://dx.doi.org/10.1034/j.1600-0773.2003.920106.x.

[21] M.C. Ramirez-Tortosa, M.D. Mesa, M.C. Aguilera, J.L. Quiles and L. Baro, Oral administration of a turmeric extract inhibits LDL oxidation and has hypocholesterolemic effects in rabbits with experimental atherosclerosis. Atherosclerosis, 147 (1999) 371-378. http://dx.doi.org/10.1016/S0021-9150 (99)00207-5.

[22] A. Duvoix, R. Blasius, S. Delhalle, M. Schnekenburger and F. Morceau, Chemopreventive and therapeutic effects of curcumin. Cancer Lett., 223 (2005) 181-190. http://dx.doi.org/10.1016/j.canlet.2004.09.041.

[23] K. Polasa, T.C. Raghuram and T.P. Krishna, Turmeric (Curcuma longa L.) induced reduction in urinary mutagens. Food Chem. Toxicol., 29 (1991) 699-706. http://dx.doi.org/10.1016/0278-6915(91)90128-T.

[24] H.G. Anwarul, J. Abdul, N. Muhammad and M. Kashif, Pharmacological basis for the use of turmeric in gastrointestinal and respiratory disorders. Life Sci., 76 (2006) 3089-3105.

[25] A.K. Chowdhury, M. Ahson, S.K. Nazrul Islam and Z.U. Ahmed, Efficacy of aqueous extract of garlic and allicin in experimental shigellosis in rabbits. Indian J. Med. Res., 93 (1991) 33-36.

[26] H. Yoshida, N. Iwata, H. Katsuzaki, R. Naganawa, K. Ishikawa, H. Fukuda, T. Fujino and A. Suzuki, Antimicrobial activity of a compound isolated from an oil-macerated garlic extract. Biosci. Biotechnol. Biochem. 62 (1998)1014-1017. http://dx.doi.org/10.1271/bbb.62.1014.

[27] A.T. Fleischauer, C.H. Poole, and L. Arab, Garlic consumption and cancer prevention: meta-analyses of colorectal and stomach cancers. Am. J. Clin. Nutr. 72 (2000) 1047-1052.

[28] S.G. Sundaram and J.A. Milner, Diallyl disulfide inhibits the proliferation of human tumor cells in culture. Biochem. Biophys. Acta 1315 (1996) 15-20. http://dx.doi.org/10.1016/0925-4439 (95)00088-7.

[29] Y. Karasaki, S. Tsukamoto, K. Mizusaki, T. Sugiura and S. Gotoh, A garlic lectin exerted an antitumor activity and induced apoptosis in human tumor cells. Food Res. Int., 34 (2001) 7-13. http://dx.doi.org/10.1016/S0963-9969 (00)00122-8.

[30] A. Duraka, H.S. Ozturk, E. Olcay and, C. Guven, Effects of garlic extract supplementation on blood lipid and antioxidant parameters and atherosclerotic plaque formation process in cholesterol-fed rabbits. J. Herbal Pharmacother., 2 (2002) 19-32. http://dx.doi.org/10.1080/J157v02n02_03.

[31] V.G. Kumar, K.P. Surendranathan, K.G. Umesh, D.R. Gayathri Devi and M.R. Belwadi, Effect of onion (Allium cepa Linn.) and garlic (AlliumSativum Linn.) on plasma triglyceride content in Japanese quail (Coturnix coturnix japonicum). Indian J. Exp. Biol., 41 (2003) 88-90.

[32] R. Peyghan, M.D. Powell and M.R. Zadkarami, In vitro effect of garlic extract and metronidazole against Neoparamoeba pemaquidensis, page 1987 and isolated amoebae from Atlantic salmon. Pak. J. Biol. Sci., 11 (2008) 41-47. http://dx.doi.org/10.3923/pjbs.2008.41.47.

[33] T. Ghazanfari, Z.M. Hassan, and A. Khamesipour, Enhancement of peritoneal macrophage phagocytic activity against Leishmania major by garlic (Allium sativum) treatment. J. Ethnopharmacol., 103 (2006) 333-337. http://dx.doi.org/10.1016/j.jep.2005.08.026.

[34] A.J. Nok, S. Williams and P.C. Onyenekwe, Allium sativum-induced death of African trypanosomes. Parasitol. Res., 82 (1996) 634-637. http://dx.doi.org/10.1007/s004360050177.

[35] A. Wahba, Studies on the efficacy of garlic extract on cryptosporidiosis in experimentally infected mice. Egypt. J. Agric. Res., 81 (2003) 793803.

[36] F. H. Toulah and M. M. Al-Rawi, Efficacy of garlic extract on hepatic coccidiosis in infected rabbits (Oryctolagus cuniculus): histological and biochemical studies. J. Egypt Soc. Parasitol., 37 (3) (2007) 957-968.

[37] D. Bensky and A. Gamble, Herbs that expel parasites, In: Chinese Herbal Medicine: Materia Medica, Eastland Press Inc., Seattle, Washington (1993); 441-444.

[38] U. H. Ahsan, K. A. Meraj and S. Rasool Effect of Supplementing Allium Sativum (Garlic) and Azadirechta Indica (Neem) Leaves in Broilers Feed on their Blood Cholesterol, Triglycerides and Antibody Titer. Int. J. Agri. Biol., 1(3) (1999) 125-127.

[39] E.J.L. Soulsby, Helminthes, Arthropods and Protozoa of Domesticated Animals, 6th Ed. Bailliere and Tindall, London (1978).

[40] N.M. Elbahy, A.M. Mokhbattly and M.E. Verginia, Comparative clinicopathological studies on garlic ethanolic extract and halofuginone compound against coccidiosis in chicken. Kafr Elsheikh Vet. J., 1(1) (2006).

[41] R.E. Khalafalla, U. Müller, M. Shahiduzzaman, V. Dyachenko, A.Y. Desouky, G. Alber and A. Daugschies, Effects of curcumin (diferuloylmethane) on Eimeria tenella sporozoites in vitro. Parasitol Res., 108 (4) (2011) 879-886. http://dx.doi.org/10.1007/s00436-0102129-y. 
[42] P.L. Long and L.P. Joyner, A guide to laboratory techniques used in the study and diagnosis of avian coccidiosis. Folia Vet. Lat., 6 (1976) 201-217.

[43] A. Petrie and P. Watson, "Statistics for Veterinary and Animal Science." 1st Ed. The Black well Science Ltd, United Kingdom (1999) PP 90 $99,110-115$

[44] L.R. McDougald and W.M. Reid, Coccidiosis.In Diseases of Poultry, 10th Edition, B. W. Calnek, ed. Iowa State University Press, Ames, IA. (1997)P 865-883.

[45] A.B. Idris, D.I. Bounous, M.A. Goodwin, J. Brown and E.A. Krushinskie, Lack of correlation between microscopic lesion scores and gross lesion scores in commercially grown broilers examined for small intestinal Eimeria spp. coccidiosis. Avian Diseases, 41 (1997) $388-391$. http://dx.doi.org/10.2307/1592194.

[46] H.S. Lillehoj, C.H. Kim, Jr. CL. Keeler and S. Zhang, Immunogenomic Approaches to Study Host Immunity to Enteric Pathogens. Poultry Science, 86 (2007) 1491-1500. http://dx.doi.org/10.1093/ps/86.7.1491.

[47] P.C. Allen, H.D. Danforth and P.C. Augustine, Dietary modulation of avian coccidiosis. Int. J. Parasitol., 28 (1998) 1131-1140. http://dx.doi.org/10.1016/S0020-7519(98)00029-0.

[48] G. Eraslan, Y. Cam, M. Eren and B.C. Liman, Changes in malondialdehyde level and catalase activity and effect of toltrazuril on these parameters in chicks infected with Eimeria tenella. Bull. Vet. Inst. Pulawy, 48 ((2004) 251-254.

[49] M.M. Chan, N.S. Adapala and D. Fong, Curcumin overcomes the inhibitory effect of nitric oxide on Leishmania. Parasitol Res., 96 (1) (2005) 49-56. http://dx.doi.org/10.1007/s00436-005-1323-9.

[50] R.S. Policegoudra, K. Abiraj, D.C. Gowda and S.M. Aradhya, Isolation and characterization of antioxidant and antibacterial compound from mango ginger (Curcuma amada Roxb.) rhizome. Journal of Chromatography B, 852 (2007) 40-48. http://dx.doi.org/10.1016/j.jchromb.2006.12.036.

[51] A. Sodsai, P. Piyachaturawat, S. Sophasan, A. Suksamrarn and M. Vongsakul, Suppression by Curcuma comosa Roxb. of pro-inflammatory cytokine secretion in phorbol-12-myristate-13- acetate stimulated human mononuclear cells. International Immunopharmacology, 7 (2007) 524- 531. http://dx.doi.org/10.1016/j.intimp.2006.12.013

[52] K. Mannangatti and M. Narayanasamy, Antifungal protein from a medicinal plant, Curcuma caesia Roxb. Journal of Biotechnology, 136 (2008) p90. http://dx.doi.org/10.1016/j.jbiotec.2008.07.204.

[53] P. C. Allen and H. D. Danforth, Effects of dietary supplementation with n-3 fatty acid ethyl esters on coccidiosis in chickens. Poult. Sci., 77 (1998) 1631-1635. http://dx.doi.org/10.1093/ps/77.11.1631.

[54] J. Sikkema, J.A.M. De Bont and B. Poolman, Mechanisms of membrane toxicity of hydrocarbons. Microbiol. Rev., 59 (1995) $201-222$.

[55] P. Mikaili, S. Maadirad, M. Moloudizargari, S.H. Aghajanshakeri and S. Shadi, Therapeutic Uses and Pharmacological Properties of Garlic, Shallot, and Their Biologically Active Compounds. Iran J. Basic Med. Sci., 16 (2013) 1031-1048.

[56] H.P. Koch and D.L. Lawson, The Science and Therapeutic Application of Allium sativum L. and Related species. 2nd Ed. Printed in the United States of America (1996).

[57] R. Pentz, Z. Guo, G. Kress, D. Mulller, B. Mulller and C.P. Siegers, Standardization of garlic powder preparations by the estimation of free and hydrolysable SH groups. Planta Med., 56 (1990) 691. http://dx.doi.org/10.1055/s-2006-961370.

[58] Y. Ueda, M. Kawajiri, N. Miyamura, and R. Miyajima, Content of some sulfur - containing components and free amino acids in various strains of garlic. J. Jpn. Soc. Food Sci. Technol., 38 (1991) 429- 34. http://dx.doi.org/10.3136/nskkk1962.38.429.

[59] C.A. Herrick and C.E. Holmes, Effect of sulfur on coccidiosis in chickens. Vet. Med., 31 (1936) 390- 391

[60] Y.M. Saif, H.J. Barnes, J.R. Glisson, A.M. Fadly, L.R. McDougald and D.E. Swayne, Diseases of Poultry 11th ed. Iowa State Press (2003).

[61] V. Naidoo, L. McGaw, S. Bisschop, N. Ducan and J. Eloff, The value of plant extracts with antioxidant activity in attenuating coccidiosis in broiler chickens. Vet. Parasitol., 153 (2008) 214-9 http://dx.doi.org/10.1016/j.vetpar.2008.02.013.

[62] M.A. Dkhil, A.S. Abdel-Baki, F. Wunderlich, H. Sies and S. Al-Quraishya, Anticoccidial and antiinflammatory activity of garlic in murine Eimeria papillata infections. Veterinary Parasitology, 175 (2011) 66-72. http://dx.doi.org/10.1016/j.vetpar.2010.09.009.

[63] H.A. El-Banna, Amera Abd El Latif and M. Soliman, Anticoccidial Activity of Allium Sativum and Aloe Vera in Broilers. International Journal for Agro Veterinary and Medical Sciences.doi:10.5455/ijavms.167 (2012). http://dx.doi.org/10.5455/ijavms.167.

[64] A.D. Fetouh and M.L. Naji, Effect of Nigella Sativa and Curcuma Longa on Experimental Eimeria Tenella Infections in Chicks. Egyptian Journal of Medical Microbiology, 16(4) (2007)

[65] A. M. Yosseff, D. H. Mansour, T.M. Ramadan, A. A. Dessouki, Comparative clinicopathological studies on the effect of some herbal plants as anticoccidial agents in broiler chickens. 8th Sci. Conf., Egyptian Veterinary poultry Association (2007).

[66] R.Z. Abbas, Z. Iqbal, M.N. Khan, M.A. Zafar, and Zia, M.A. Anticoccidial activity of Curcuma longa L. in Broiler Chickens. Brazilian Archives of Biology and Technology, 53 (1) (2010) 63-67. http://dx.doi.org/10.1590/S1516-89132010000100008. 